\title{
Human Kallikrein 8 Expression in Salivary Gland Tumors
}

\author{
Mark R. Darling · Sam Tsai · Linda Jackson-Boeters • \\ Thomas D. Daley $\cdot$ Eleftherios P. Diamandis
}

Received: 12 May 2008 / Accepted: 3 June 2008/Published online: 3 July 2008

(c) Humana 2008

\begin{abstract}
The human kallikrein 8 protein (KLK8) is expressed in many normal tissues including esophagus, skin, testis, tonsil, kidney, breast, and salivary gland, and is found in biological fluids including breast milk, amniotic fluid, seminal fluid and serum. It has also been shown to be a biomarker and prognostic factor for breast cancer. The aim of this study was to determine whether KLK8 is expressed in salivary gland tissues and salivary gland tumors (both benign and malignant), in order to compare normal with tumor tissues. Pleomorphic adenomas, adenoid cystic carcinomas, polymorphous low grade adenocarcinomas, acinic cell carcinomas, mucoepidermoid carcinomas, and adenocarcinomas NOS of both minor and major salivary glands were examined. The results of this study indicate that most salivary gland tumors show high levels of expression of KLK8.
\end{abstract}

M. R. Darling $(\bowtie) \cdot$ L. Jackson-Boeters · T. D. Daley Division of Oral Pathology, Department of Pathology, University of Western Ontario, 1151 Richmond Street, London, ON, Canada N6A 5C1

e-mail: mark.darling@schulich.uwo.ca

S. Tsai

Faculty of Medicine \& Dentistry, University of Alberta,

Edmonton, AB, Canada

E. P. Diamandis

Department of Pathology and Laboratory Medicine, Mount Sinai Hospital, Toronto, ON, Canada

E. P. Diamandis

Department of Laboratory Medicine and Pathobiology,

University of Toronto, Toronto, ON, Canada
Keywords Kallikreins - Human kallikrein 8 . Salivary gland tumors · Prognostic markers . Immunohistochemistry

$\begin{array}{ll}\text { Abbreviations } \\ \text { PA } & \text { Pleomorphic adenoma } \\ \text { ACC } & \text { Adenoid cystic carcinoma } \\ \text { PLGA } & \text { Polymorphous low grade adenocarcinoma } \\ \text { ACI } & \text { Acinic cell carcinoma } \\ \text { MEC } & \text { Mucoepidermoid carcinoma } \\ \text { ANOS } & \text { Adenocarcinoma not otherwise specified } \\ \text { KLK } & \text { Human kallikrein protein } \\ \text { KLK } & \text { Human kallikrein gene } \\ \text { RT } & \text { Room temperature } \\ \text { PBS } & \text { Phosphate-buffered saline } \\ \text { Pab } & \text { Polyclonal antibody } \\ \text { DAB } & 3,3^{\prime} \text {-Diaminobenzidine }\end{array}$

\section{Introduction}

Human tissue kallikreins (KLKs) are a subfamily of serine proteases encoded by 15 genes, localized in tandem on human chromosome 19q13.4 [1-4]. Recently, many novel kallikrein genes have been characterized and a detailed map of the human kallikrein gene locus has been constructed [4]. The members of the kallikrein family are now implicated in a wide range of normal and pathological processes, either independently or as part of a proteolytic cascade [4, 5]. Most kallikreins show trypsin- and chymotrypsin-like activity [6].

Numerous studies have shown that kallikreins are overexpressed in ovarian, breast, and prostate carcinomas and that some may be important new biomarkers for 
diagnosis and monitoring of many cancer types [7-9]. The overexpression of kallikreins in malignant tumors has been linked with both favourable and poor patient prognosis [4].

Several studies have shown that most human kallikreins are expressed in the salivary glands $[1,2,10]$. It is thus possible that some members of this family may be valuable markers for differential diagnosis, sub-typing and monitoring of patients with salivary gland carcinomas.

The kallikrein 8 gene $(K L K 8)$ was described by Yoshida et al. as the kallikrein-like gene, $K L K-8 /$ neuropsin [11]. The KLK8 protein is expressed in many normal tissues, most notably in esophagus, skin, testis, tonsil, kidney, breast and salivary gland; and in biological fluids such as breast milk, amniotic fluid, seminal fluid and serum [12]. To date, there are few reports linking KLK8 to cancer. It may be a biomarker and prognostic indicator for ovarian cancer [9].

The aim of this study was to determine whether KLK8 is expressed in salivary gland tissues and salivary gland tumors (both benign and malignant), in order to compare normal with tumor tissues. This is the first report of KLK8 expression in salivary gland tumors.

\section{Materials and Methods}

Archival formalin fixed-paraffin embedded tumor tissues from the Division of Oral Pathology, Department of Pathology, University of Western Ontario were cut in 5 micron sections, and stained using a standard immunoperoxidase technique. Twenty six pleomorphic adenomas (PA), 23 adenoid cystic carcinomas (ACC), 13 polymorphous low grade adenocarcinomas (PLGA), 7 ACIs (ACI), 24 mucoepidermoid carcinomas (MEC), 8 adenocarcinomas NOS (ANOS) of salivary gland origin and 57 normal salivary gland controls were used in the study. The tumors were diagnosed according to criteria published in the Atlas of Tumor Pathology: Tumors of the Salivary Glands of the Armed Forces Institute of Pathology [13]. Appropriate matching negative controls (primary antibody omitted from tissue slides), one for each experimental tumor section, and positive controls (skin), were used.

A KLK8-specific rabbit polyclonal antibody raised against full length recombinant KLK8 protein produced in yeast, and tested for specificity and sensitivity, was used at a dilution of 1:4,000. The recombinant KLK8 protein was produced and purified by ultra sensitive immunoassay as described previously [14].

Staining procedures included deparaffinization in xylene for 13 min with two changes of xylene at room temperature (RT) followed by transfer through graded alcohols and rehydration. Endogenous peroxidase activity was blocked with fresh $3 \% \mathrm{H}_{2} \mathrm{O}_{2}$ in methanol for $5 \mathrm{~min}$. The sections were rinsed in PBS for $10 \mathrm{~min}$ on a shaker. Antigen retrieval was achieved by immersing the slides in boiling citrate buffer ( $\mathrm{pH} \mathrm{6.0)} \mathrm{for} 10 \mathrm{~min}$ at high power, and $10 \mathrm{~min} 50 \%$ power in a microwave oven. They were then rinsed in water and PBS for $5 \mathrm{~min}$, blocked in 10\% horse serum for $30 \mathrm{~min}$ at RT in a humidified chamber, and incubated with the KLK8 primary rabbit polyclonal antibody (Pab) for $1 \mathrm{~h}$ at RT. After two washes in PBS, the biotinylated goat antirabbit secondary antibody (1/200 dilution, prepared in 10\% horse serum, Vector Elite Kit, Vector Laboratories, Burlington, $\mathrm{ON}$ ) was applied for $30 \mathrm{~min}$ at RT. After two rinses with PBS, the freshly prepared ABC reagent was applied for $30 \mathrm{~min}$ at RT. The enzymatic reaction was developed in a freshly prepared solution of 3,3'-diaminobenzidine tetrahydrochloride (DAB) (Sigma-Aldrich, Oakville, ON) for $5 \mathrm{~min}$. The sections were then rinsed with water, counterstained with hematoxylin for $3 \mathrm{~min}$, dehydrated, cleared with xylene and mounted.

A proportion score and intensity score using a welldocumented system was used to assess KLK8 immunostaining $[15,16]$. The proportion score represents the estimated fraction of positively staining tumor cells (where $\mathbf{0}=$ none; $\mathbf{1}<1 / 100 ; \mathbf{2}=(1 / 100)-(1 / 10) ; \mathbf{3}=(1 / 10)-(1 /$ $3) ; \mathbf{4}=(1 / 3)-(2 / 3) ; \mathbf{5}>2 / 3)$. For staining intensity, the score is represented by the estimated average staining intensity of positively staining tumor cells (where $\mathbf{0}=$ none; $\mathbf{1}=$ weak; $\mathbf{2}=$ intermediate; $\mathbf{3}=$ strong). The overall amount of positive staining was then expressed as the sum of the proportion and intensity scores (ranges: 0 for negative staining and 2-8 for positive staining). In normal salivary gland tissue, ductal and acinar cells were scored separately. In tumor tissue, cells lining duct-like structures and non-ductal cells were scored for extent of positive and intensity of staining. For the purposes of this study, ductlike cells are regarded as those cells that line the lumens of duct-like structures within tumor tissue, while non-ductal cells are any cells in the tumor tissue that are not obviously lining ducts. Cells lining pseudocystic spaces, such as those in ACC, were scored as non-ductal cells. For MEC, squamous cells, mucous cells and intermediate cells were scored separately. These cells were identified by two experienced histopathologists, and based on morphological descriptions in the Atlas of Tumor Pathology, Armed Forces Institute of Pathology [13]. Intermediate cells are round to ovoid cells, about two to three times larger than lymphocytes, mucous cells which are large and contained obvious mucin droplets were easy to identify, while epidermoid cells are large polygonal cells. The immunohistochemically stained slides were also compared with hematoxylin and eosin, and mucicarmine stained tissues to facilitate cell identification. Non-epithelial cells were not scored. The staining was assessed by three trained examiners to achieve consistency by comparison and correlation of assessments in order to reduce inter-examiner variability. 
Wilcoxon and Dunn's multiple comparisons tests were used, where appropriate, for the statistical analyses. Statistical significance was set at $P<0.05$.

\section{Results}

The KLK8 immunoreactivity was assessed in the cytoplasm of cells that stained positively (Figs. 1-5). There were no significant differences in staining of normal minor (mucous) and major (mucous and serous) salivary glands, and so the data for all normal glands were combined. In general, all the tumors showed a relatively high overall staining for both ductal and non-ductal cells. The data are summarized in Tables 1 and 2.

In comparing total scores of normal salivary gland tissue and all malignant salivary gland tumors, the $P$-value was 0.0268 , showing a significant, although not striking, difference with higher expression in the malignant tumors, particularly because of MEC and ANOS. MECs expressed significantly more KLK8 than normal salivary gland $(P=0.0011)$. Adenocarcinoma NOS expressed significantly more KLK8 than normal salivary glands $(P=0.0068)$.

Comparison of all benign tumors and malignant tumors showed that both MEC and ANOS expressed more KLK8 than PA $(P=0.0174$ and 0.0435 respectively).

Comparison of malignant tumors showed that MEC and ANOS expressed higher levels of KLK8 than PLGA $(P=0.0005$ and 0.0132 respectively).

Comparison of ductal and non-ductal cells also yielded some significant differences. Ductal cells were seen and scored only in normal salivary gland tissue, PA, ACC and PLGA. All ductal cells showed a significantly increased

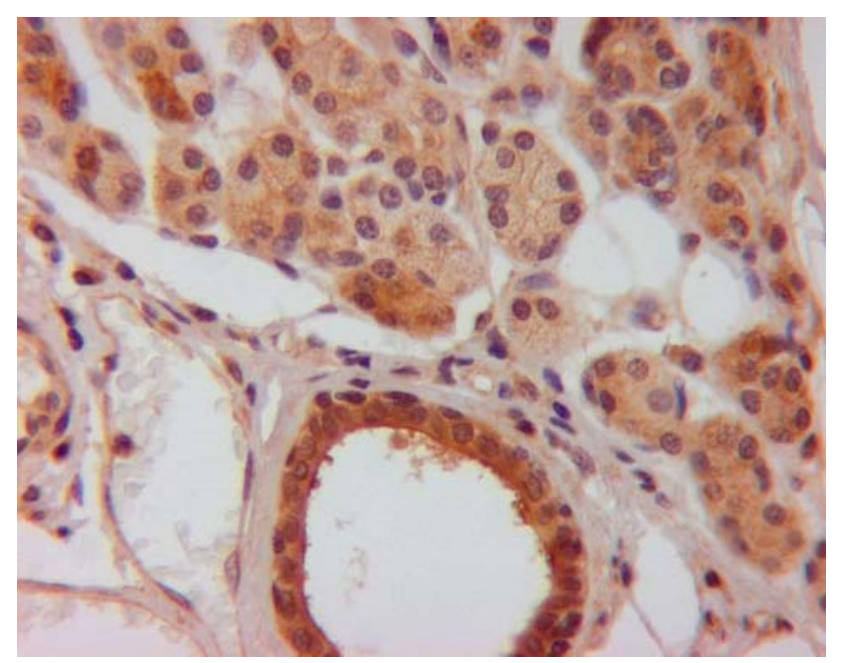

Fig. 1 KLK8 staining (brown staining in cytoplasm of cells) in normal salivary gland tissue (original magnification $\times 400$ )

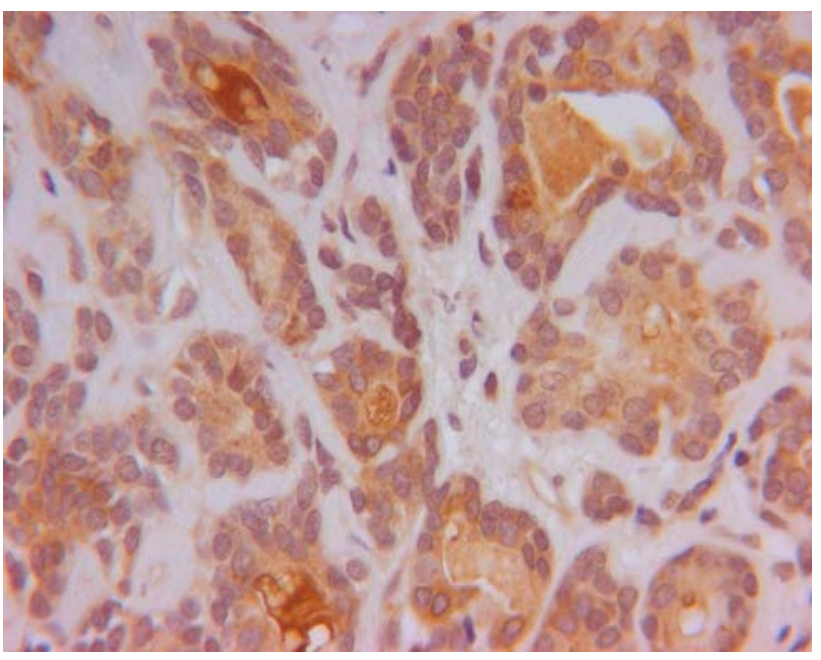

Fig. 2 KLK8 staining (brown staining in cytoplasm of cells) in PA (original magnification $\times 400$ )

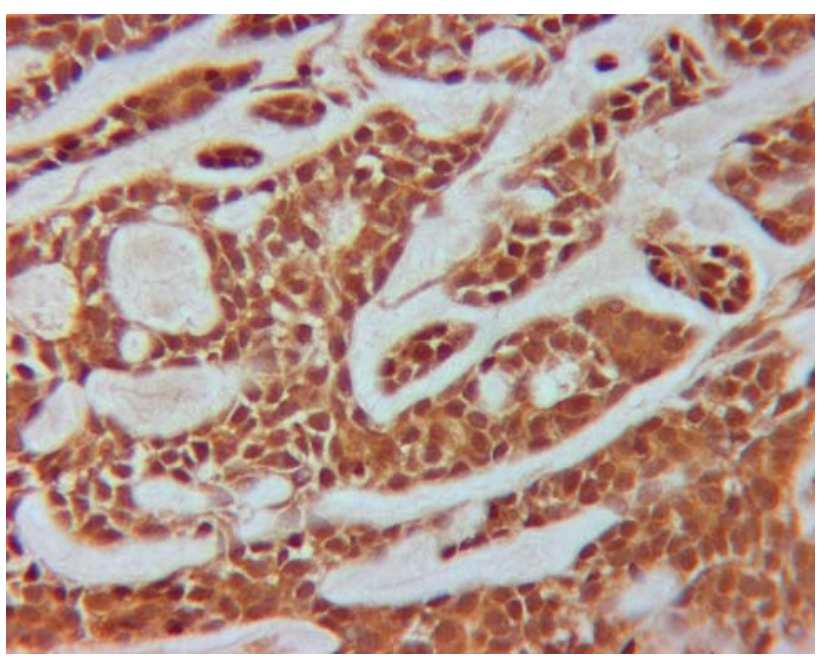

Fig. 3 KLK8 staining (brown staining in cytoplasm of cells) in ACC (original magnification $\times 400$ )

expression of KLK8 over non-ductal cells $(P=0.0001)$. Normal ductal cells showed significantly higher KLK8 expression than non-ductal cells of normal salivary gland tissue $(P=0.0001)$. All tumor ductal cells showed significantly higher KLK8 expression than all tumor nonductal cells $(P=0.0042)$. Ductal cells in PA showed significantly higher staining than non-ductal cells in PA $(P=0.019)$. PA ductal cells also stained significantly higher than PLGA ductal cells $(P=0.015)$. ACC nonductal cells exhibited significantly more staining than nonductal cells in normal salivary gland tissues $(P=0.0436)$.

Using ANOVA, differences between the three cell types (mucous, squamous and intermediate) were extremely significant $(P=0.0007)$ in MECs. A Dunn pairs comparison showed that mucous cells exhibited more KLK8 staining than intermediate cells $(P<0.001)$. 


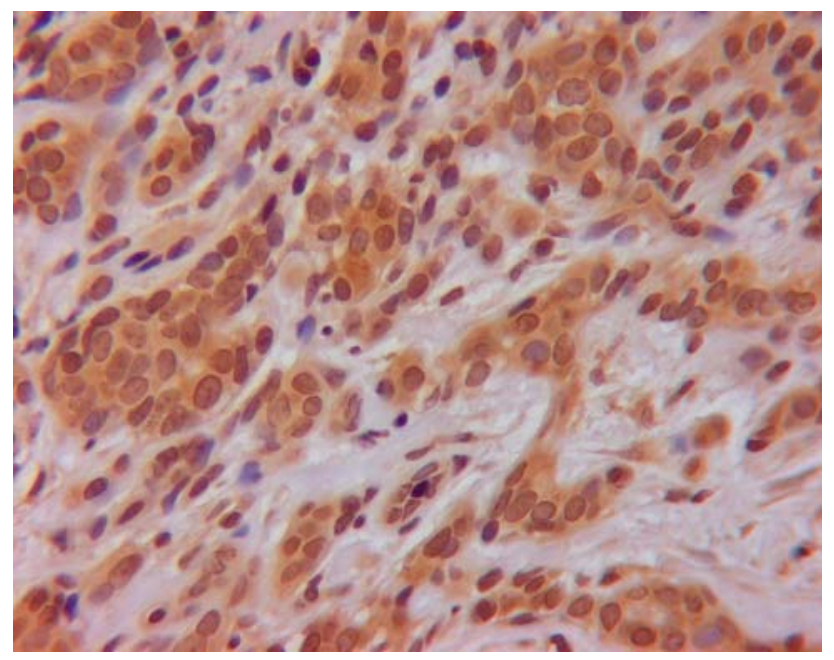

Fig. 4 KLK8 staining (brown staining in cytoplasm of cells) in PLGA (original magnification $\times 400$ )

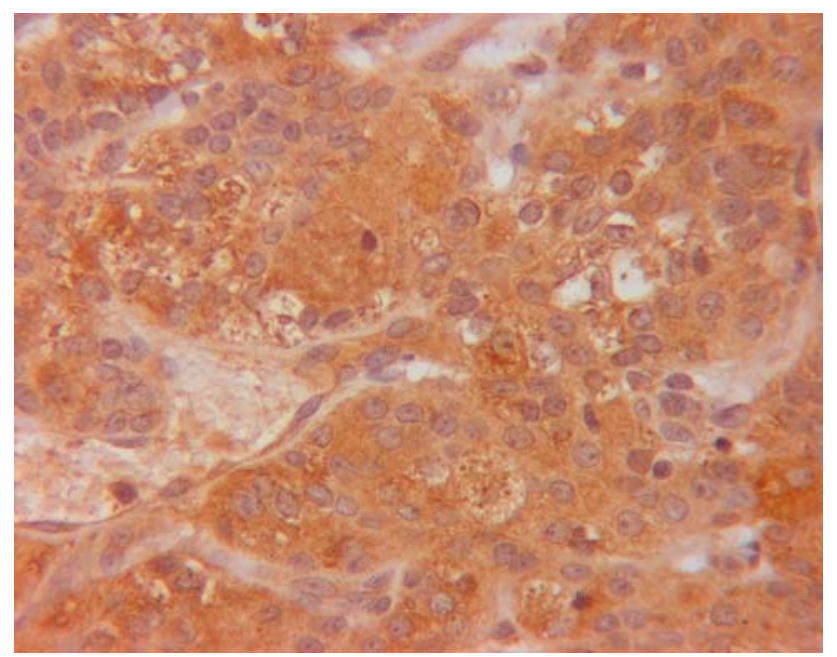

Fig. 5 KLK8 staining (brown staining in cytoplasm of cells) in MEC (original magnification $\times 400$ )

\section{Discussion}

The kallikrein gene locus on chromosome 19q13.4 has been well characterized $[1,4]$. The family consists of 15 genes encoding for secreted serine proteases. Human tissue kallikreins (KLKs) are the largest contiguous group of proteases within the genome and are becoming a research focus because of their association with various forms of cancer. Among the proteins encoded, prostate specific antigen (PSA which is KLK3) has been shown to be a valuable marker for prostate cancer [1-4, 7-9]. A number of other kallikreins, such as KLK6, KLK7, KLK8, KLK10, KLK11, KLK13 and KLK14, have also been associated with various forms of malignancy [1-4, 7-9].

KLK8 is found in high levels in normal tissue extracts of esophagus and skin and in fetal tissue extracts of ureter and tonsil, while it is present in lower levels in testis, tonsil, kidney, breast, salivary gland, lymph nodes and fallopian tubes. It is found in high levels in breast milk but is also present in other biological fluids such as amniotic fluid, follicular fluid, seminal fluid, serum and cerebrospinal fluid [12].

Kishi et al. demonstrated that KLK8 was present in high levels in ascites fluid and serum of ovarian cancer patients, and proposed it as a novel biomarker for ovarian cancer [17]. The $K L K 8$ gene is up-regulated in ovarian cancer [18] and its higher expression is associated with a favourable outcome [19]. Magklara et al., using reversed transcription PCR on ovarian tumor tissue extracts, reported that $K L K 8$ and its spliced variants were expressed very frequently and that full-length KLK8 expression is an independent and favourable prognostic marker for ovarian cancer. Patients with higher $K L K 8$ expression in the tumor have lower grade disease, lower residual tumor left after surgery, live longer, and relapse less frequently [19, 20]. Borgono et al. reported similar results using ELISA to quantify KLK8 in 136 ovarian tumor extracts, showing that women with KLK8 positive tumors had lower grade tumors, and significantly longer progression-free and overall survival than KLK8 negative patients [21].

$K L K 8$ is downregulated in breast cancer tissues and cell lines [22]. On the other hand, $K L K 8$, along with several other kallikrein genes, could be primarily up-regulated by $17 \beta$-estradiol and, to a lesser degree, by other steroid hormones in hormone receptor-positive breast cancer cell lines MCF-7 and T-47D, suggesting a coordinated kallikrein expression as part of a complex regulatory mechanism that controls the expression of these genes and also their downstream physiological function [23].

Cané et al. found that $K L K 8$ is highly over-expressed in cervical cancer cell lines, suggesting that $K L K 8$ has the potential to become a useful diagnostic tool for monitoring response to therapy as well as to detect early recurrence after treatment and may also serve as a novel target antigen for the therapy of cervical tumors refractory to standard treatment modalities [24].

It has been suggested that expression of $K L K 8$ may be regulated by sex steroid hormones in endometria, and that elevated KLK8 mRNA and KLK8 expression is an early event in endometrial carcinogenesis. This may potentially serve as a useful early biomarker for the detection of endometrial carcinomas [25].

In non-small cell lung cancer, KLK8 appears to suppress tumor cell invasiveness by degrading fibronectin, thereby suppressing integrin signalling, and also retards cancer cell motility by inhibiting actin polymerization [26]. In a mouse model, KLK8 suppresses tumor growth and invasion in vivo. In patients with non-small cell lung cancer, too, the time to postoperative recurrence was longer for early- 
Table 1 Staining in ductal cells and non-ductal cells and total scores for immunostaining of major and minor salivary glands, and salivary tumors for human kallikrein 8 (Average staining $\pm \mathrm{SD}^{\mathrm{a}}$ )

\begin{tabular}{|c|c|c|c|c|c|c|c|c|}
\hline \multirow[t]{2}{*}{ 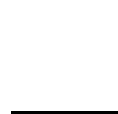 } & \multirow[t]{2}{*}{$n^{\mathrm{b}}$} & \multicolumn{3}{|c|}{ Ductal cells } & \multicolumn{3}{|c|}{ Non-ductal cells } & \multirow{2}{*}{$\begin{array}{l}\text { Average of total scores } \\
\text { of ductal \& non-ductal }\end{array}$} \\
\hline & & $\mathrm{P}^{\mathrm{c}}$ & $\mathrm{I}^{\mathrm{d}}$ & Total & $\mathrm{P}$ & I & Total & \\
\hline Normal & 57 & $4.9 \pm 0.5$ & $2.4 \pm 0.8$ & $7.3 \pm 1.0$ & $4.9 \pm 0.2$ & $1.8 \pm 0.6$ & $6.7 \pm 0.7$ & $7.0 \pm 0.8$ \\
\hline PA & 26 & $4.9 \pm 0.3$ & $2.7 \pm 0.5$ & $7.6 \pm 0.6$ & $4.4 \pm 0.6$ & $2.0 \pm 0.7$ & $6.4 \pm 1.2$ & $7.0 \pm 0.9$ \\
\hline ACC & 23 & $4.8 \pm 0.5$ & $2.4 \pm 0.7$ & $7.2 \pm 1.0$ & $4.6 \pm 1.1$ & $2.2 \pm 0.9$ & $6.7 \pm 1.7$ & $7.0 \pm 1.4$ \\
\hline PLGA & 13 & $5.0 \pm 0.0$ & $2.0 \pm 0.6$ & $7.0 \pm 0.6$ & $5.0 \pm 0.0$ & $1.8 \pm 0.5$ & $6.8 \pm 0.5$ & $6.9 \pm 0.5$ \\
\hline ACI & 7 & & & & $5.0 \pm 0.0$ & $2.0 \pm 0.8$ & $7.0 \pm 0.8$ & $7.0 \pm 0.8$ \\
\hline ANOS & 8 & & & & $5.0 \pm 0.0$ & $2.6 \pm 0.7$ & $7.6 \pm 0.7$ & $7.6 \pm 0.7$ \\
\hline MEC & 24 & & & & & & & $7.5 \pm 0.5$ \\
\hline
\end{tabular}

${ }^{\text {a }}$ For staining score definition, see text. SD = Standard deviation

b Number of samples

${ }^{c} \mathrm{P}=$ Proportion score

${ }^{\mathrm{d}} \mathrm{I}=$ Intensity score

Table 2 KLK8 staining in mucoepidermoid carcinomas of major and minor glands

\begin{tabular}{|c|c|c|c|c|c|c|c|c|c|}
\hline \multirow[t]{2}{*}{$n=24$} & \multicolumn{3}{|c|}{ Squamous cells } & \multicolumn{3}{|c|}{ Mucous cells } & \multicolumn{3}{|c|}{ Intermediate cells } \\
\hline & $\mathrm{P}^{\mathrm{c}}$ & $\mathrm{I}^{\mathrm{d}}$ & Total & $\mathrm{P}$ & I & Total & $\mathrm{P}$ & I & Total \\
\hline Average $^{a}$ & 5.0 & 2.5 & 7.5 & 5.0 & 2.2 & 7.1 & 5.0 & 2.9 & 7.9 \\
\hline $\mathrm{SD}^{\mathrm{b}}$ & 0.0 & 0.5 & 0.5 & 0.2 & 0.6 & 0.6 & 0.0 & 0.4 & 0.4 \\
\hline
\end{tabular}

${ }^{a}$ For staining score definition, see text

b $\mathrm{SD}=$ Standard deviation

${ }^{\mathrm{c}} \mathrm{P}=$ Proportion score

${ }^{\mathrm{d}} \mathrm{I}=$ Intensity score

stage patients with high KLK8 expression than for patients with low KLK8 expression.

KLK8 is a serine protease which exhibits trypsin-like activity and can degrade casein, fibronectin, gelatin, collagen type IV, fibrinogen and high-molecular weight kininogen. Its activity is inhibited by typical serine protease inhibitors $[6,27]$. This suggests that it is implicated in extracellular matrix protein degradation in the areas surrounding KLK8-producing cells [6].

Tissue kallikreins have now been implicated in proteolytic cascade pathways in normal physiology and cancer [28-30]. These cascades are operative and regulatory in semen liquefaction, skin desquamation, psoriasis, skin cancer and prostate cancer. KLK8 is a part of the proteolytic cascade in semen liquefaction, skin desquamation, several skin diseases and squamous cell carcinoma of the skin, as well as prostate cancer progression [28]. KLK5, 6 and 13 are also involved in some of these cascades. It is therefore conceivable that a proteolytic cascade involving KLK8 and the other kallikreins may be operative in salivary gland cancers. We are currently investigating the expression of most kallikreins in salivary gland cancers.

\section{Conclusion}

In conclusion, KLK8 was present in relatively high levels in ductal cells, as well as in non-ductal cells, of normal salivary gland tissues and benign and malignant salivary gland tumors. Our experiments have shown us that generally, KLK8 is significantly higher in ductal cells than in non-ductal cells, and that in general, malignant tumors expressed higher levels of KLK8 than normal salivary gland tissue and benign tumors. Where there have been good follow up studies in cancer patients, e.g. ovarian cancer, overexpression of KLK8 has been shown to predict a better prognosis [19]. This hypothesis has to be tested with salivary gland tumors, and studies are underway to determine the correlation of the expression of various kallikreins in malignant salivary gland tumors with patient outcome (e.g. tumor recurrence, survival rates, and prognosis). We have previously demonstrated the high

Table 3 Comparison of immunohistochemical staining of human kallikreins 3, 5, 6, 13 and 8 in normal salivary gland tissue (minor and major glands) and salivary gland tumors [31-33]

\begin{tabular}{llllll}
\hline & \multicolumn{4}{c}{ Average of total scores } & for ductal and non-ductal cells \\
\cline { 2 - 6 } & KLK3 & KLK5 & KLK6 & KLK13 & KLK8 \\
\hline Normal & 0.0 & 0.0 & 6.0 & 6.8 & 7.0 \\
PA & 0.0 & 0.2 & 3.7 & 5.8 & 7.0 \\
ACC & 0.0 & 0.2 & 3.8 & 7.2 & 7.0 \\
PLGA & 0.0 & 0.0 & 5.8 & 7.4 & 6.9 \\
ACI & 0.0 & 0.0 & 6.0 & 7.3 & 7.0 \\
ANOS & 0.0 & 0.4 & 6.8 & 7.8 & 7.6 \\
MEC & 0.0 & 0.4 & 6.1 & 6.8 & 7.5 \\
\hline
\end{tabular}

${ }^{\text {a }}$ For staining score definition, see text

b No ductal cells were seen in ACI, ANOS and MEC. Squamous cells, intermediate cells and mucous cells were scored in MEC 
expression of KLK13, and absence of, or low expression of KLK3, KLK5 and KLK6 in salivary gland tumors (see Table 3 for comparison with results for KLK8) [31-33]. As suggested by Paliouras and Diamandis, the kallikreins which are upregulated may be due to a coordinated activation [34], which in salivary gland tumors may be controlled by as yet unrecognised mechanisms, meriting further investigation. In addition, the kallikrein expression profile of individual malignant salivary tumors, and its correlation with tumor spread, recurrence and prognosis, is currently being investigated.

Acknowledgments The authors are grateful to Linda Grass for technical advice and to the National Organization for Rare Disorders which provided funding for this study.

\section{References}

1. Diamandis EP, Yousef GM, Luo LY. The human kallikrein gene family-implications in carcinogenesis. Trends Endocrinol Metab. 2000;11:54-60.

2. Yousef GM, Diamandis EP. The new human tissue kallikrein gene family: structure, function and association to disease. Endocr Rev. 2001;22:184-204.

3. Borgono CA, Michael IP, Diamandis EP. Human tissue kallikreins: physiologic roles and applications in cancer. Mol Cancer Res. 2004;2:257-80.

4. Borgono CA, Diamandis EP. The emerging roles of human tissue kallikreins in cancer. Nat Rev Cancer. 2004;4:876-90.

5. Yousef GM, Diamandis EP. Human tissue kallikreins: a new enzymatic cascade pathway? Biol Chem. 2002;383:1045-57.

6. Rajapakse S, Ogiwara K, Takano N, et al. Biochemical characterization of human kallikrein 8 and its possible involvement in the degradation of extracellular matrix proteins. FEBS Lett. 2005;579:6879-84.

7. Diamandis EP, Yousef GM. Human tissue kallikreins: a family of new cancer biomarkers. Clin Chem. 2002;48:1198-1205.

8. Diamandis EP, Yousef GM. Human tissue kallikrein gene family: a rich source of novel disease biomarkers. Expert Rev Mol Diagn. 2001;1:182-90.

9. Obiezu C, Diamandis E. Human tissue kallikrein family: applications in cancer. Cancer Lett. 2005;224:1-22.

10. Petraki CD, Papanastasiou PA, Karavana VN, et al. Cellular distribution of human tissue kallikreins: immunohistochemical localization. Biol Chem. 387;2006:653-63.

11. Yoshida S, Taniguchi M, Hirata A, et al. Sequence analysis and expression of human neuropsin cDNA and gene. Gene. 1998;213:9-16.

12. Kishi T, Grass L, Soosaipillai A, et al. Human kallikrein 8: immunoassay development and identification in tissue extracts and biological fluids. Clin Chem. 2003;49:87-96.

13. Ellis GL, Auclair PL. Tumors of the salivary glands. In: Rosai J, Sobin LH, editors. Atlas of tumor pathology, Third Series, Fascicle 17. Washington, D.C.: Armed Forces Institute of Pathology; 1996. p. 39-56, 155-228.

14. Black MH, Magklara A, Obiezu CV, et al. Development of an ultrasensitive immunoassay for human glandular kallikrein with no cross-reactivity from prostate-specific antigen. Clin Chem. 1999;45:790-9.
15. Allred DC, Clark GM, Elledge R, et al. Association of p53 protein expression with tumor cell proliferation rate and clinical outcome in node-negative breast cancer. J Natl Cancer Inst. 1993;85:200-6.

16. Tuck AB, O'Malley FP, Singhal H, et al. Osteopontin expression in a group of lymph node negative breast cancer patients. Int J Cancer. 1998;79:502-8.

17. Kishi T, Grass L, Soosaipillai A, et al. Human kallikrein 8, a novel biomarker for ovarian carcinoma. Cancer Res. 2003;63:2771-4.

18. Yousef GM, Polymeris ME, Yacoub GM, et al. Parallel overexpression of seven kallikrein genes in ovarian cancer. Cancer Res. 2003;63:2223-7.

19. Magklara A, Scorilas A, Katsaros D, et al. The human KLK8 (neuropsin/ovasin) gene: identification of two novel splice variants and its prognostic value in ovarian cancer. Clin Cancer Res. 2001;7:806-11.

20. Shigemasa K, Tian $X, G$ L, et al. Human kallikrein 8 (KLK8/ TADG-14) expression is associated with an early clinical stage and favorable prognosis in ovarian cancer. Oncol Rep. 2004;11:1153-9.

21. Borgono CA, Kishi T, Scorilas A, et al. Human kallikrein 8 protein is a favorable prognostic marker in ovarian cancer. Clin Cancer Res. 2006;12:1487-93.

22. Yousef GM, Yacoub GM, Polymeris ME, et al. Kallikrein gene downregulation in breast cancer. Br J Cancer. 2004;90:167-72.

23. Paliouras M, Diamandis EP. Coordinated steroid hormonedependent and independent expression of multiple kallikreins in breast cancer cell lines. Breast Cancer Res Treat. 2007;102:7-18.

24. Cané S, Bignotti E, Bellone S, et al. The novel serine protease tumor-associated differentially expressed gene-14(KLK8/Neuropsin/Ovasin) is highly overexpressed in cervical cancer. Am J Obstet Gynecol. 2004;190:60-6.

25. Jin H, Nagai N, Shigemasa K, et al. Expression of tumor-associated differentially expressed Gene-14 (TADG-14/KLK8) and its protein KLK8 in uterine endometria and endometrial carcinomas. Tumour Biol. 2006;27:274-82.

26. Sher YP, Chou CC, Chou RH, et al. Human kallikrein 8 protease confers a favorable clinical outcome in non-small cell lung cancer by suppressing tumor cell invasiveness. Cancer Res. 2006;66:11763-70.

27. Kishi T, Cloutier SM, Kundig C, et al. Activation and enzymatic characterization of recombinant human kallikrein 8. Biol Chem. 2006;387:723-31.

28. Pampalakis G, Sotiropoulou G. Tissue kallikrein proteolytic cascade pathways in normal physiology and cancer. Biochim Biophys Acta. 2007;1776:22-31.

29. Emami N, Diamandis EP. Human tissue kallikreins: a road under construction. Clin Chim Acta. 2007;381:78-84.

30. Yoon H, Laxmikanthan G, Lee J, et al. Activation profiles and regulatory cascades of the human kallikrein-related peptidases. J Biol Chem. 2007;282:31852-64.

31. Darling MR, Jackson-Boeters L, Daley TD, et al. Human kallikrein 6 expression in salivary gland tumors. J Histochem Cytochem. 2006;54:337-42.

32. Darling MR, Jackson-Boeters L, Daley TD, et al. Human kallikrein 13 expression in salivary gland tumors. Int J Biol Markers. 2006;21:106-10.

33. Darling MR, Tsai S, Jackson-Boeters L, et al. Human kallikrein 3 (prostate specific antigen) and human kallikrein 5 expression in salivary gland tumors. Int J Biol Markers. 2006;21:201-5.

34. Paliouras M, Diamandis EP. The kallikrein world: an update on the human tissue kallikreins. Biol Chem 2006;387:643-52. 